\title{
An Empirical Investigation into Blended Learning Effects on Tertiary Students and Students Perceptions on the Approach in Botswana
}

\author{
Gofaone Kgosietsile Kebualemang \\ Faculty of Computing \\ Botho University \\ Gaborone, Botswana
}

\author{
Alpheus Wanano Mogwe \\ Faculty of Computing \\ Botho University \\ Gaborone, Botswana
}

\begin{abstract}
The aim of the research was to conduct an empirical investigation into blended learning (BL) effects on tertiary students and students' perceptions on the approach. This purpose was objective driven, following three objectives which were identified as 1) to assess the impact of $B L$ on students enrolled in Tertiary institutions; 2) to assess tertiary students' perceptions on the BL mode; and lastly 3 ) to establish the extent to which BL is accepted in a typical institution or university learning environment. An extensive literature review exercise was carried out which led to identification of two research questions to be used to meet the objectives and the purpose of the study. The research questions were 1) Does blended learning (BL) transform learners' attitudes towards learning and improves results? 2) Does blended learning (BL) revolutionizes learners' critical thinking levels and dispositions? Through the research the authors were specifically trying to elucidate and understand the BL mode and the effects it has on students, and their perceptions on it. The researcher followed the quantitative approach with the aid of using a questionnaire to further understand the effects of BL mode on students and their perceptions on the same, after reviewing several literatures. The findings indicated that the BL mode has a positive impact on the students, and students' perceptions on the BL mode were also positive. These findings led to positive conclusions on the BL mode, substantiating the literature review findings on the same. In the light of the findings, and the objectives of the study, the authors concluded the study by proposing a framework which could be used for monitoring $B L$ effects on tertiary students and students' perceptions on the approach, as the results from the study indicated a positive outlook on the BL mode.
\end{abstract}

Keywords-Blended learning; blended learning effects; Students'perceptions

\section{INTRODUCTION}

Blended learning (BL) has become an integral part of modern education. This has seen many institutions of higher learning providing a new perspective in education delivery and attainment through the use of blended learning mode. With this mode, a new phrase "the world is flat" was coined [1], meaning attainment of education has become accessible to everyone everywhere - global students [2], [3].

Blended learning is an integration of the online mode with the traditional mode of face-to-face to offer class activities in a pedagogically valuable planned manner [2], [4]-[7]. The mode involves certain portions of the activities of face-to-face being replaced through the usage of online activities [2], [8]. This diverse mode gives institutions a variety of educational approaches to use. With many institutions moving to this mode, the traditional way of face to face has seen its decline in institutions which are techno-savvy and oriented. BL growth and impact is currently undisputable in the educational field [9].

Various literatures indicate a rise in its usage both in institutions of higher education and or tertiary institutions [2], [5], [10]-[12]. It has become an acceptable pedagogical approach which is believed to change the whole educational scenario and the traditional classroom set up. Many benefits have been touted such as but not limited to pedagogical richness, access to knowledge and social interaction. In addition, some challenges have been noted such as but not limited to financial constraints to set up technologies related to usage of BL. These challenges, though, they have not hampered some of the tertiary institutions in Botswana to adopt the usage of the BL mode. Botho University is one institution which stands as an example of the provision of such mode. Other institutions have been lagging behind to embrace this mode.

\section{BACKGROUND TO THE PROBLEM}

\section{A. Background Scenario}

Botswana has made strides in education, with enrollment numbers indicating an increase on yearly basis and tertiary institutions accounting for $11.4 \%$ [13]. The delivery mode in many tertiary institutions has remained a traditional one, involving face-to-face with little or none at all to integrate modern technologies such as the usage of online technologies to supplement the educational system. Botho University is one institution which has embraced the use of BL, and it is vital to investigate how this has impacted students.

BL is being embraced all over the world [9]. Therefore, educational institutions in Botswana need to rethink on the inclusion of the blended learning mode. Institutions ought to embrace BL trends for reform, or face decline in their educational goals due to the use of the outdated approach only. Moreover, other studies [14], [15] have indicated the dynamism brought by technology in peoples' everyday lifestyles together with its importance in education and learning. 
It would be argued that the assimilation of technology into an institutional teaching and delivery mode is an asset to its educational needs but when institutions lag in its embracement, causes to that should be identified. Thus, questions remain on why are Botswana institutions lagging behind in implementation of BL mode? What are the effects of BL on students? What are the students' perceptions on BL? Therefore, this study seeks to understand the BL effects on tertiary students and their perceptions on the same.

\section{B. Problem Statement}

The lagging behind of institutions in Botswana to embrace blended learning is a concern which ought to be investigated. Therefore, it is important to understand the effects of BL on tertiary students and students' perceptions on the approach on the institutions that have embraced BL mode. Understanding its effects on students and students' perception will pave way to know whether this influences the lagging behind of institutions to embrace the same. Due to the blended learning mode being a new educational delivery mode, it has not been tested or vigorously investigated in the Botswana scope, hence the lingering problem is the effects of this mode on tertiary students and students' perceptions on the approach.

\section{AIM AND OBJECTIVES}

A. Aim

The study is aimed at conducting an empirical investigation into blended learning effects on tertiary students and students' perceptions on the approach.

\section{B. Objectives}

1) To assess the impact of BL on students enrolled in Tertiary institutions

2) To assess tertiary students' perceptions on the BL mode.

3) To establish the extent to which BL is accepted in a typical institution or university learning environment.

\section{RESEARCH QUESTIONS}

1) Does blended learning (BL) transform learners' attitudes towards learning and improve results?

2) Does blended learning (BL) revolutionize learners' critical thinking levels and dispositions?

\section{LITERATURE REVIEW}

\section{A. What is blended learning mode}

Blended learning (BL) is the modern way of delivering education to students. Various authors agree that BL mode is an integration of the online mode with the traditional mode of face-to-face to offer class activities in a pedagogically valuable planned manner which provides flexibility [6], [16], [17]. In addition, other authors [1], [2], [8], [9], [18] support the findings related to the positives of the BL mode. The mode involves certain portions of the activities of face-to-face being replaced through the usage of online activities [2], [19].

This diverse mode gives institutions a variety of educational approaches to use which at the same time complement each other. With many institutions moving to this mode, the traditional way of face to face has seen its decline in institutions which are techno-savvy and oriented.

\section{B. Blended learning mode around the world}

There is a rise in the use of the BL mode. BL has become the acceptable pedagogical approach which is believed to change the whole educational scenario and the traditional classroom set up. Many benefits have been touted such as but not limited to pedagogical richness, access to knowledge and social interaction. In addition, some challenges have been noted such as but not limited to financial constraints to set up technologies related to usage of BL. These challenges, though, they have not hampered institutions around the world to introduce BL mode as seen from the following discussion.

Blended learning has found its way around the world. It has become a must inclusion component in the curriculum developments and educational learning. Institutions are rapidly infusing it into their education system. So and Bonk [18] have noted the increase of usage of the BL mode around the world. This has been attributed highly to the growth of usage of online and internet related gadgets. Different institutions around the world have embraced the concept, from both developed to developing countries, and BL has shown to be of positive developments in those institutions and countries.

In many of the developed and developing nations, institutions have embraced the use of blended learning. Kwak [17] states that there has been an increase of universities offering BL mode with an increase of many students embracing it. In the United Kingdom, Open University is one of the universities known for its employment of the BL mode [20]. It has helped students with greater access to educational opportunities. The use of the BL mode has helped to restructure education delivery and training programs. Amity University in India has also extensively utilized the BL mode technologies for greater access to the students' population.

\section{Blended learning effects on students}

A study carried in Iran [16], showed that BL mode has positive effects on the students. The study further showed that students easily associated and embraced a mode which included both the traditional face-to-face and the technology related mode, in which BL mode was the fit. Thus, the findings have shown a positive correlation between the usage of the BL mode and its effects on students' performance in class [17]. Kwak [17] note the importance of the BL mode environment in relation to the positive outcomes of students' results.

Mersal and Mersal [19] noted that BL mode utilizes two or more complementary approaches in the delivery of education to students. Through a study [19], BL mode was found to be effective and providing an improvement regarding satisfactory level of achievement in the education setup. Thus, this further shows the relevancy and importance of this mode in changing the educational scope to the positive scope. There was an improvement from the students who utilized BL mode in relation to course and teaching methods satisfaction [19], the same findings reached and concluded by other authors [21], [22]. 
Therefore, it can be argued that both the students' ways of learning and the subsequent quality of learning is closely related and forms part of their learning experiences and the embracement of the mode of learning they encounter. With the technology having broken the barriers of education attainment, the traditional way of learning which was constrained to class rooms and face-to-face learning, is by itself not enough in this modern era. It shows that alone it cannot meet the learners' expectations hence it draws on the negative side, but its infusion to modern ways of learning leading to a BL mode makes this a more robust learning approach. These are the same conclusions reached by Owston [23]. Students have shown that BL mode offers convenience, is more engaging and offers a better perspective of learning which gave a positive feedback on the overall satisfaction with BL mode. Thus, BL mode contributes more to students' attitudes towards course/subjects when it is compared to the traditional learning models. With it, it nurtures student critical disposition and levels leading to a positive correlation between student attitudes towards subjects or courses being undertaken.

\section{METhODOLOGY}

Following a systematic approach in data collection is an important aspect in research [24]. Saunders [25] states that a methodology is a requirement for every research being conducted. This is sustained by other authors [26]-[28]. According to Oates [29], a selection of a methodology follows a careful analysis of various elements or factors, in which one of them is working well with other methods and research tools. This would help to deem the methodology suitable for the study to be conducted.

The most common methodologies are the qualitative and quantitative methodologies. These two methodologies can be used together to form what is known as a mixed methodology approach. Both this approaches have got advantages and disadvantages as they address various research issues. The researcher chose to follow the quantitative approach to complete this study.

According to Chilisa and Preece [28], quantitative approach is an approach driven by the investigators questions in which various issue perspectives are collected from the subjects' view point in line with the questions posed by the investigator [30]. It follows suitable techniques and metrics per problem statement. Through this approach there is a heavy reliance on numerical and statistical analysis, which is the strongest strength of the quantitative approach which helps it to evade biasness in a study [27], [31], [32].

Thus, the above argument, sustains the argument that the quantitative approach is regarded as a rigid approach which is not subject to bias through subjective interpretations [26], [33]. This approach employs a variety of techniques such as selfcompletion questionnaires, surveys, and structured observations to fulfill its mandate. The researcher employed self-completion questionnaire technique, with a structured questionnaire designed and developed for usage to obtain responses.

Patton and Cochran [34] states that utilization of self- completion questionnaire coupled with the quantitative approach makes it easier to measure and analyze data. This leads to a conducive and simple platform to measure the attitudes, behaviors and performance of respondents. This can then be easily changed into quantifiable graphs and charts. Moreover, the usage of this approach coupled with the questionnaire technique, helps to reach a wider audience and capture more data to be used [25], [35]. The researcher used a larger audience to ameliorate the downside associated with this approach. Attention was put in place to ensure the relevance and integrity of the study so that there is no diversion from the core mandate through the usage of a pilot study.

The main drawback for the quantitative methodology is the skills needed to comprehend the various formulae and numbers during the data analysis [29].

\section{SAMPLING}

According to Terre Blanche [36] and Kumar [37] it is vital to locate a population to carry the sample on. A sample constitutes a portion which becomes the target population representing the overall population [36], [37]. This portion becomes the basis for estimating a fact, outcome or situation to represent a larger population. A population constitutes of all members to which the study makes a reference to, and are able to be part of it [37]. The sampled population was taken from Botho University in Gaborone with the target population being all Botho University students. The sample was done in Botho University, Gaborone. The sample helps to reduce costs as only a limited number of people are involved in the study. Carrying out research on a bigger population or whole population is expensive both in terms of resources, time and money. This sample is selected through a probability or non-probability method. A variety of decision making criteria are followed to reach conclusion on the specified sample such as the behavior of the targeted audience, their background, location and type of people.

As for this study, the researcher with the aid of online sample size calculators sampled 200 participants using a confidence interval of \pm 3 with confidence level set at $95 \%$. The threshold for the needed sample size was 169 with a distribution of 200 participants. The researcher distributed 200 questionnaires in Botho University Gaborone campus. During distribution, no cognizant efforts were put into consideration in relation to gender or age.

The authors used a simple random sampling technique for distribution of the questionnaire. Chilisa and Preece [28] states that this is one of the basic sampling techniques which gives equal chances of inclusion and participation to each and every member of the general population.

\section{RESULTS FINDINGS AND ANALYSIS}

Presentation of this section closely follows the layout of the questionnaire. The questionnaire was divided into three parts, namely, 1) usage of Blended learning and its assistance in knowledge gaining; 2) Blended learning and my attitude to learning; and 3) Blended learning on results. These parts had their own sub-questions in likert scale of Strongly Agree, Agree, Neutral, Disagree and Strongly Disagree. 
Table 1 shows that 200 questionnaires were distributed and, $189(94 \%)$ were collected from the participants of the study. $6 \%$ which is a total of 11 were not brought back due to unforetold reasons from participants. The threshold of the study wanted at least $169(84.5 \%)$ of questionnaires collected, and this was met with the collection of $94 \%$ of the questionnaires surpassing the threshold by $9.5 \%$.

TABLE. I. QUESTIONNAIRE SUMMARY

\begin{tabular}{|l|l|l|}
\hline Questionnaire Summary & Raw Numbers & $\%$ \\
\hline Brought Questionnaire & 189 & $94 \%$ \\
\hline Questionnaire Not Brought & 11 & $6 \%$ \\
\hline Total Questionnaire Given Out & 200 & $100 \%$ \\
\hline
\end{tabular}

A. Part A: Usage of Blended learning and its assistance in knowledge gaining

This is the first part of the questionnaire, and it had six (6) questions. The objective of this part was to understand from the participants how blended learning impact on knowledge gaining. The questions were:

1) I enjoy using blended learning.

2) Blended learning improves my access to class content and interaction with other learners.

3) Blended learning improves my access to module content.

4) The use of blended learning components enhanced each other.

5) The use of web resources is useful for my modules/subjects.

6) The technologies used for blended learning (videos, web, audios, internet) are helpful in my course.

For questions in this section, it can be noted that participants agreed that BL mode impacted positively on their knowledge gaining sustaining the findings by Kwak [17]. Refer to summarized findings section (Section IX of this document) for column charts presentation as per the questions. Respondents for question 1 noted at 52\% that they agreed with the question as shown in Fig. 1. They showed that they enjoyed using $\mathrm{BL}$ mode, followed by $30 \%$ who strongly agreed to being satisfied of using the BL mode. A total of $82 \%$ enjoyed BL mode usage compared to $12 \%$. In question 2 depicted by Fig. 2, a total of $95 \%$ of the respondents are in the affirmative of the question with only $5 \%$ opposing it and $2 \%$ remaining neutral. Both these analyses indicate a strong confirmation of other studies [8], [19], [38].

Participants at an aggregate of $93 \%$ affirmed to the question stand with $41 \%$ strongly agreeing that BL improved access to module content, and 52\% agreed to the same (refer to Fig. 3). $3 \%$ remained neutral and $5 \%$ made of $3 \%$ disagreeing and $2 \%$ strongly disagreeing represented those who opposed the question. For question 4 an aggregate of $95 \%$ of the respondents agreed with the question, as indicated in Fig. 4 and $3 \%$ opposed the question. $2 \%$ of the respondents remained neutral in this question. Participants agreed that BL mode web resources and technologies were helpful at $100 \%$ for both question 5 and 6 (refer to Fig. 5 and 6, respectively). The findings sustain Mersal and Mersal [19] findings together with those of Nagel [2] that BL Modes components enhance each other to offer greater access to learning resources and class contents [39].

From the respondents, it can be concluded that the Usage of Blended learning and its assistance in knowledge gaining as addressed in Part $\mathrm{A}$ of the questionnaire and summarised findings in Fig. 1 to 6 , it is of importance to respondents. Respondents have overwhelmingly affirmed to the questions which were asked under this part, also sustaining the findings under the literature review which indicated that BL mode when correctly applied it will lead to satisfaction of students [2], [19], [21].

\section{B. Part B: Blended learning and my attitude to learning}

Under part B of the questionnaire, the researcher sought to understand how BL impacted on student attitude. This part had five questions, and below is the presentation of the findings from the questions. The questions were:

1) Blended learning has improved my Analytical skills.

2) Blended learning has helped me to be Open-Minded in approaching my course/program learning.

3) Blended learning has increased my Inquisitiveness to foster my understanding of the course/program.

4) Blended learning has increased my Self-Confidence in the course /program.

5) Blended learning has helped me to grow and be creative in my course/program in fostering innovation and problem solving.

For questions in this section it can be noted that participants agreed that BL mode has a positive impact on students' attitudes, further cementing other findings from other authors [16], [40]. Refer to summarized findings section (Section IX of this document) for pie charts presentation as per the questions.

Majority of the respondents in question 7 (refer to Fig. 7), sought to capture (if BL mode improved students' analytical skills at a combined 93\%) agreed of a BL mode, positive impact on their analytical skills. $6 \%$ of the respondents remained neutral with $1 \%$ disagreeing. Fig. 8 shows results for question 8 . In question $8,56 \%$ of the respondents agreed to the question with $34 \%$ strongly agreeing to make a total of $90 \%$ of the respondents who concurred that BL had a positive impact of making them to be open minded on their approach to their studies. $6 \%$ remained and 3\% disagreed. This also sustains the findings by various authors from various studies who have shown that BL mode impacts positively on students' analytical skills and open thinking [19], [38], [41].

In question $9,92 \%$ of the respondents agreed that the BL mode helped them to further being inquisitive to understand their course with 5\% remaining neutral and 3\% opposed as indicated by Fig. 9. The analysis for question 10 as depicted in the results in Fig. 10 indicates that at 64\%, respondents strongly agreed that BL mode increased their self confidence in their course, with $31 \%$ agreeing to the same making a total of $95 \%$ of the respondents who agreed that BL mode has a 
positive impact of increasing their self-confidence with $3 \%$ remaining neutral and $2 \%$ disagreeing. Fig. 11, indicating question 11 feedback shows that $62 \%$ strongly agreed to the question with $31 \%$ agreeing to it, bringing the affirmative respondents to a total of $93 \%$, who agreed that $\mathrm{BL}$ mode helped students to grow and be creative in their course/program to foster innovation and problem solving. Only 5\% remained neutral and a combined $2 \%$ opposed it.

The analysis shows that majority of the respondents affirmed to the questions under this part and concurred that Blended learning mode changed their attitudes to the best in relation to their learning activities. These findings sustain the findings in the literature review [19], [38], [41] that BL mode has a positive impact to students and it changes their attitudes for the best [2], [19], [23].

\section{Part C: Blended learning on results}

This was the last portion of the questionnaire which sought to understand how BL impacted on students' results and performance. This had six questions which were:

1) With blended learning, I received too much feedback from my instructors.

2) Blended Learning fostered more interaction between me and other students and the instructor.

3) The responses received helped me to focus and learn more deeply.

4) With blended learning I have improved my module/subject results.

5) Blended learning has impacted positively on the growth of my course/program GPA.

6) I enjoy using blended learning mode and would recommend it for others.

The results indicated that BL mode has a positive impact on students learning and results. Refer to summarized findings section (Section IX of this document) for column and pie charts presentation as per the questions. The questions under this section concurred with findings from various studies [17], [19], [22] that BL mode helps improve results. An individual analysis of the questions under this section found out that for question 12, respondents agreed that BL mode had an impact on the instructor feedback at $94 \%$ (refer to Fig. 12). This included a combined $46 \%$ of those who strongly agreed and $48 \%$ who agreed. $3 \%$ remained neutral with a combined $3 \%$ opposing the question. For question 13, respondents at $41 \%$ strongly agreed that BL mode fostered more interaction between learners themselves and the instructor, followed by $54 \%$ who agreed, as indicated in Fig. 13. A total of 95\% agreed that BL has a more positive impact in that regard with $2 \%$ and $1 \%$ disagreeing and strongly disagreeing, respectively. $2 \%$ of the respondents remained neutral on this question. Respondents under question 13 agreed at $87 \%$ that BL mode had the effect of making students focus and learn more deeply with $8 \%$ remaining neutral and 5\% opposing (refer to Fig. 14).

Question 15 and 16 were focused onto the results and GPA of the students. The respondents in this question noted in the affirmative of BL mode positive impact on their results with $100 \%$ affirming that due to BL mode they have improved their results (refer to Fig. 15). Respondents at $65 \%$ indicated that they strongly agreed that BL mode has a positive impact on the growth of their GPA followed by $31 \%$ who agreed and $4 \%$ who remained neutral. That is a total of $96 \%$ of the respondents agreed that BL mode has a positive impact on the growth of GPA as indicated in Fig. 16.

With respondents showing a positive outlook for the BL mode, and appreciation, many of the respondents at $96 \%$ agreed that they enjoyed using BL mode and would recommend it for others with $4 \%$ remaining neutral on the same (refer to Fig. 17). Respondents of the questionnaire indicated that they have been exposed to BL mode for at least a minimum of a year, as indicated in Fig. 18 below.

The findings of this section sustain the literature review, in which BL mode is attributed to positive results in students. Various studies have been carried out to check how BL mode impacted students' results, and it has been concluded to be a positive impact, hence the same findings in this study. A study by Mersal [19] indicated that students performed better in a BL mode set up due to its richness in providing various modes for learning. Delialioğlu [39] also notes that students' engagement in BL mode environments provides a positive growth in relation to performance. Bliuc [42] highlights the relationship between social identity, mode/approaches to learning, and academic performance as factors-and concludes that BL mode environment is more advantageous.

\section{CHARTS SUMMARISED FINDINGS}

This portion presents the analyzed findings in charts and graphs for better understanding of the previously discussed section. It augments what has already been discussed.

Part A Questions: Usage of Blended learning and its assistance in knowledge gaining

Column charts below are for all questions in Part A of the questionnaire. Refer to results findings and analysis (Section VIII) for analysis of part A.

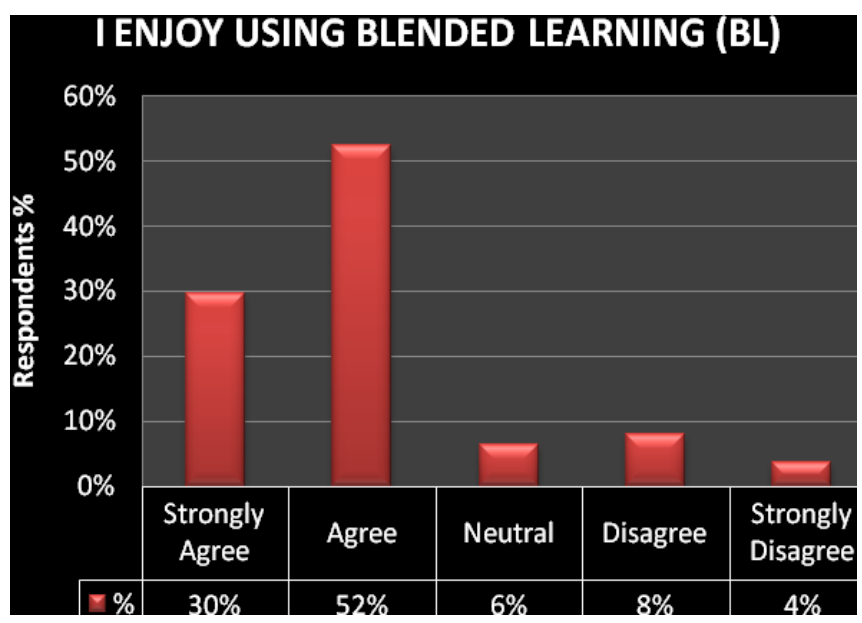

Fig. 1. Question 1 column chart 


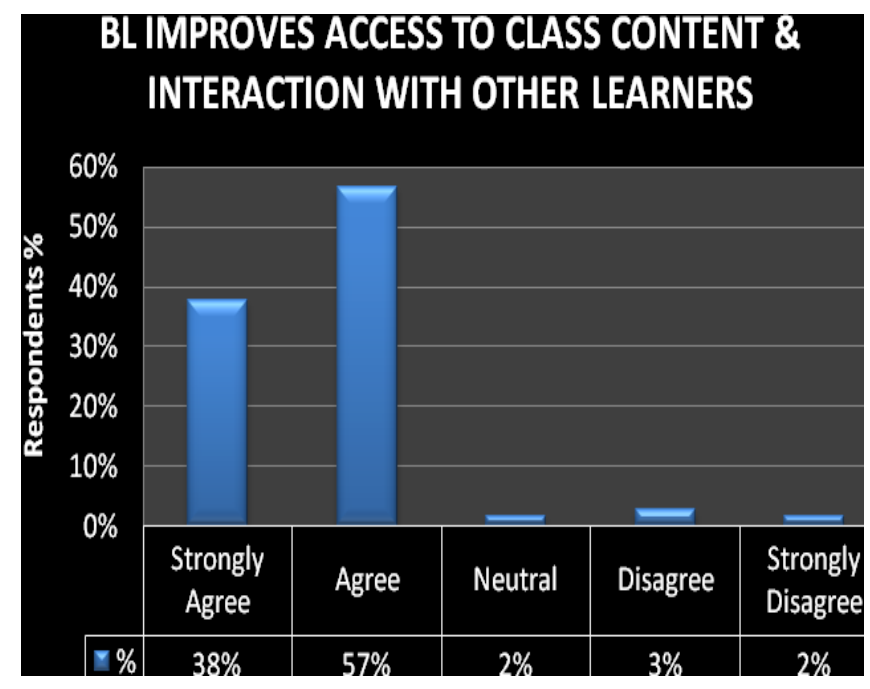

Fig. 2. Question 2 column chart

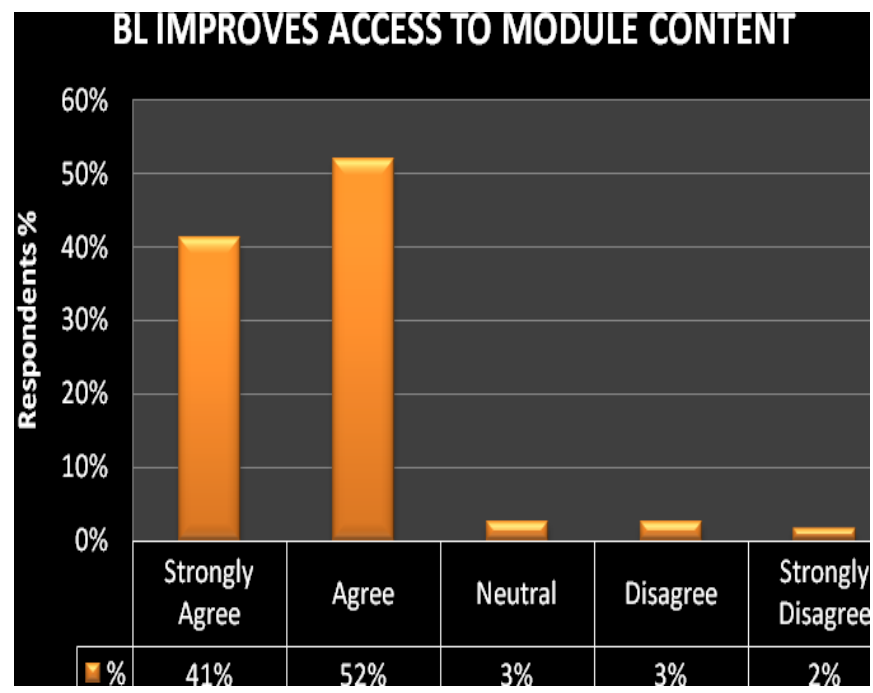

Fig. 3. Question 3 column chart

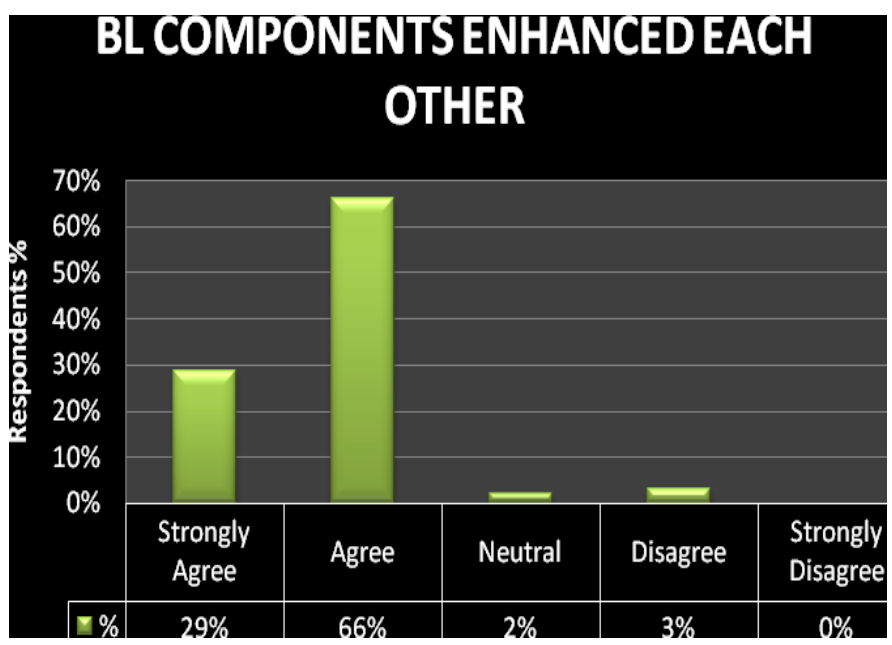

Fig. 4. Question 4 column chart

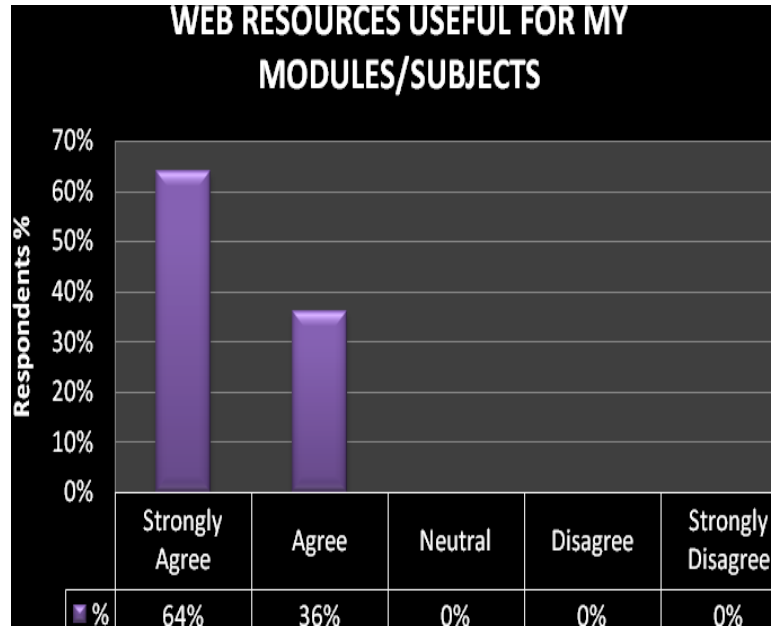

Fig. 5. Question 5 column chart

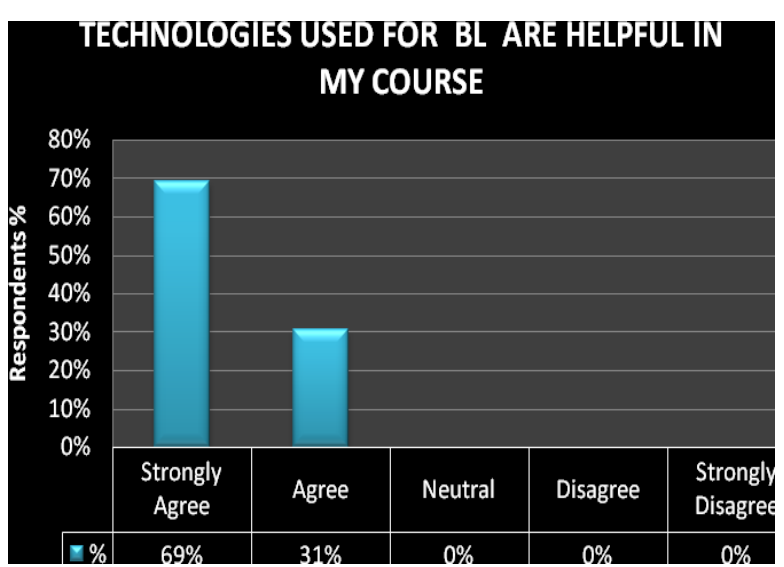

Fig. 6. Question 6 column chart

Part B Questions: Blended Learning and my attitude to learning

Pie charts below are for all questions in Part B of the questionnaire. Refer to results findings and analysis (Section VIII) for analysis of Part A.

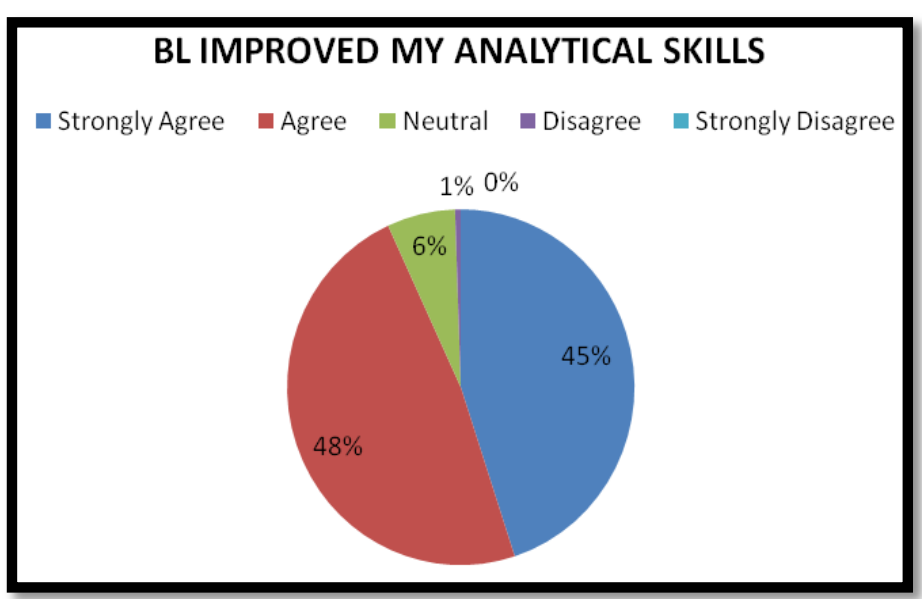

Fig. 7. Question 7 pie chart. 


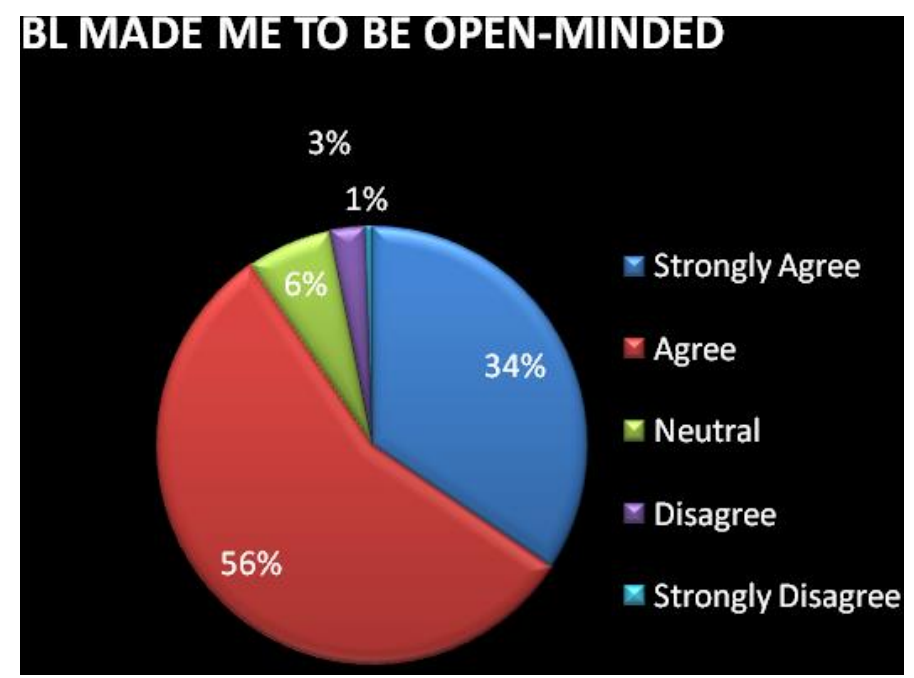

Fig. 8. Question 8 pie chart

\section{BLINCREASED MY INQUISITIVENESS TO FOSTER COURSE UNDERSTANDING}

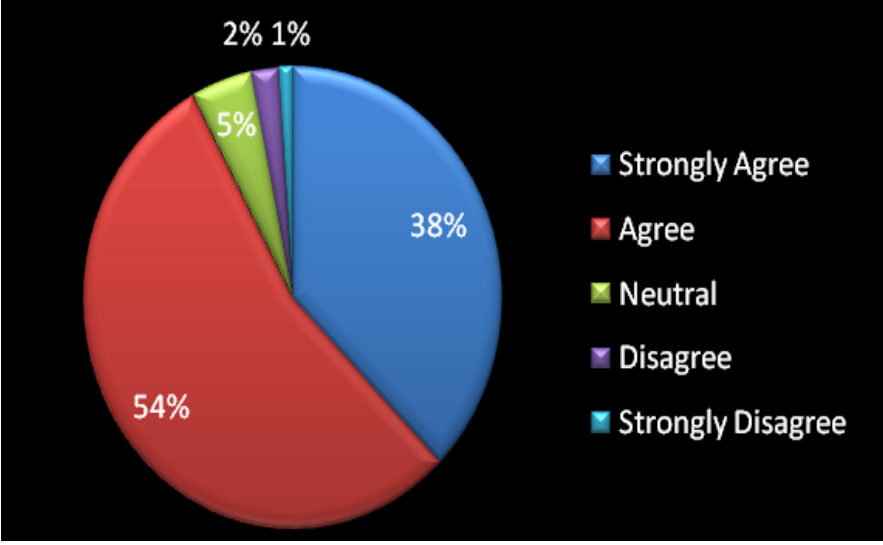

Fig. 9. Question 9 pie chart

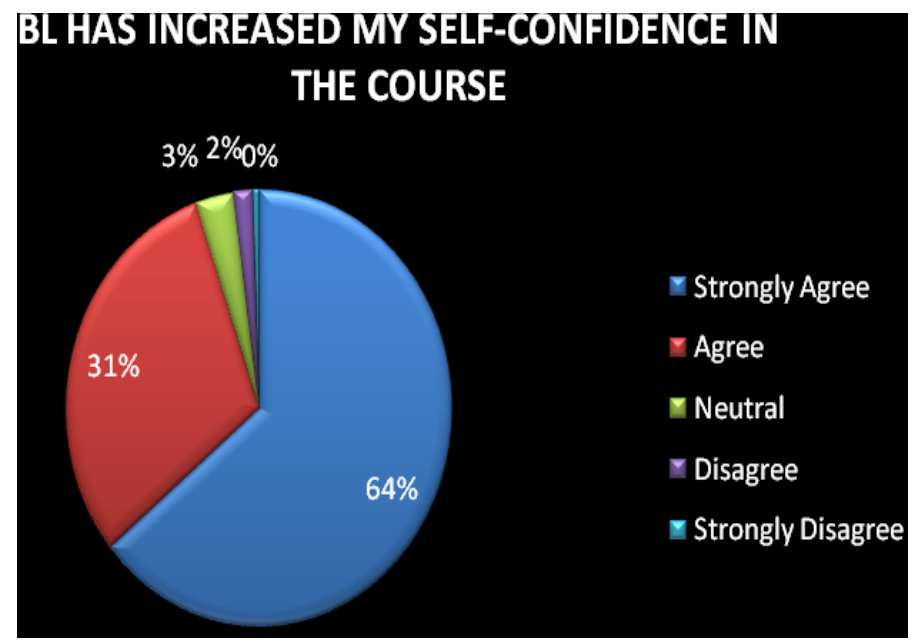

Fig. 10. Question 10 pie chart

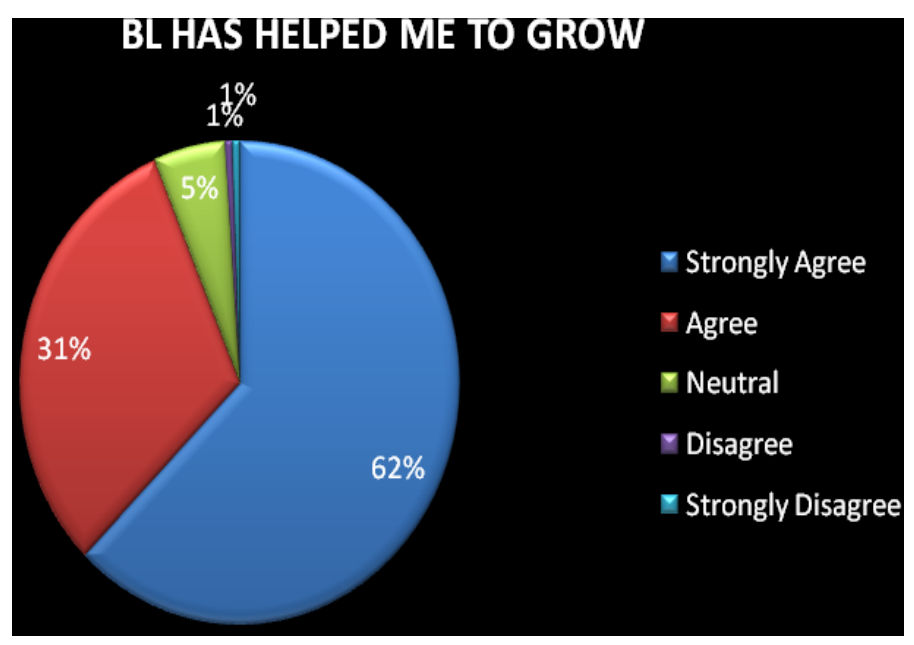

Fig. 11. Question 11 pie chart

Part C Questions: Blended learning on results

Pie charts below are for all questions in Part $\mathrm{C}$ of the questionnaire. Refer to results findings and analysis (Section VIII) for analysis of Part C.

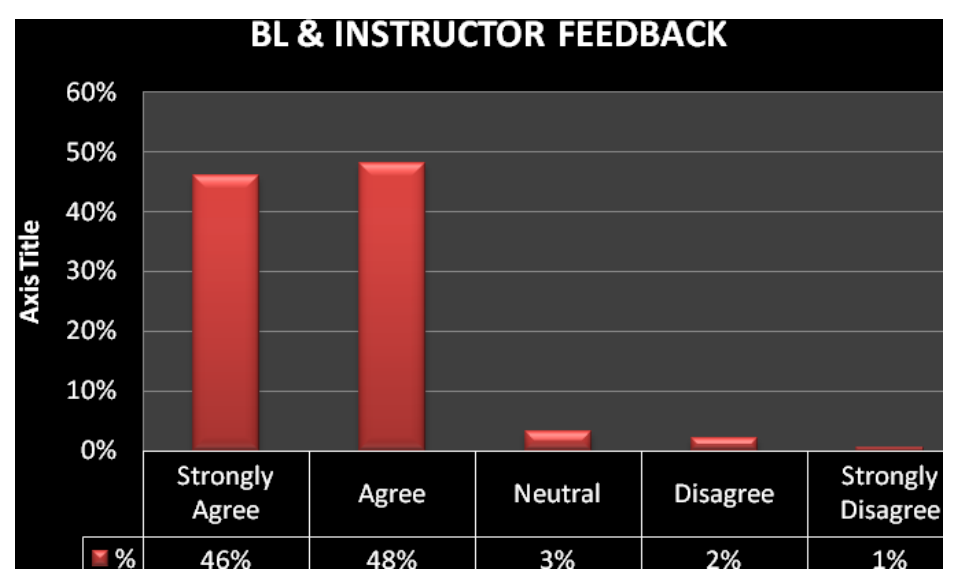

Fig. 12. Question 12 Column chart

BL FOSTERED MORE INTERACTION BETWEEN ME $\&$ OTHER STUDENTS \& THE INSTRUCTOR

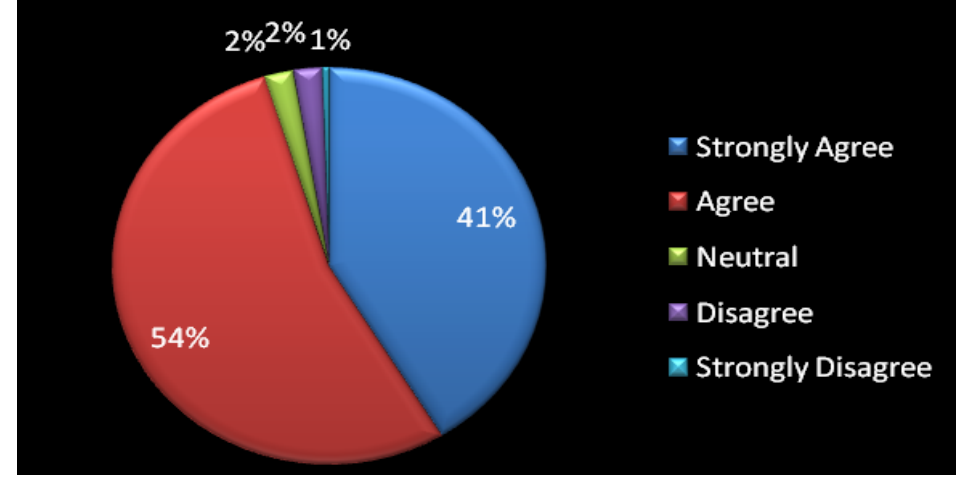

Fig. 13. Question 13 pie chart 


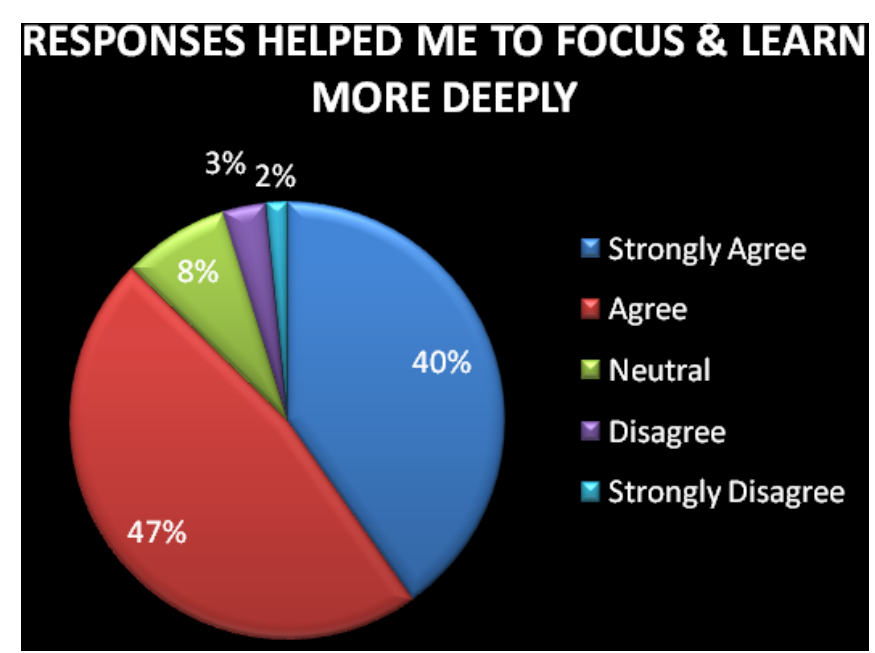

Fig. 14. Question 14 pie chart

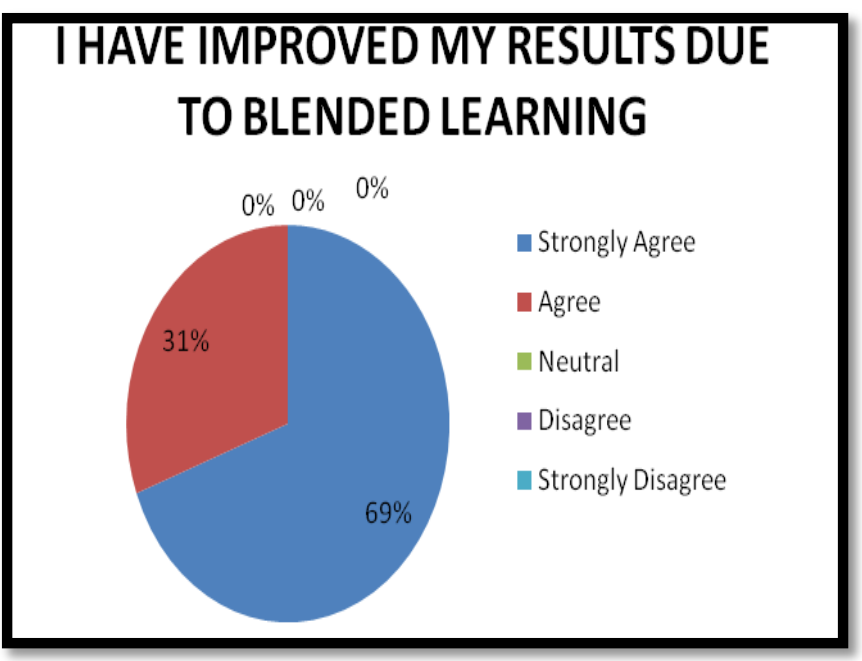

Fig. 15. Question 15 pie chart

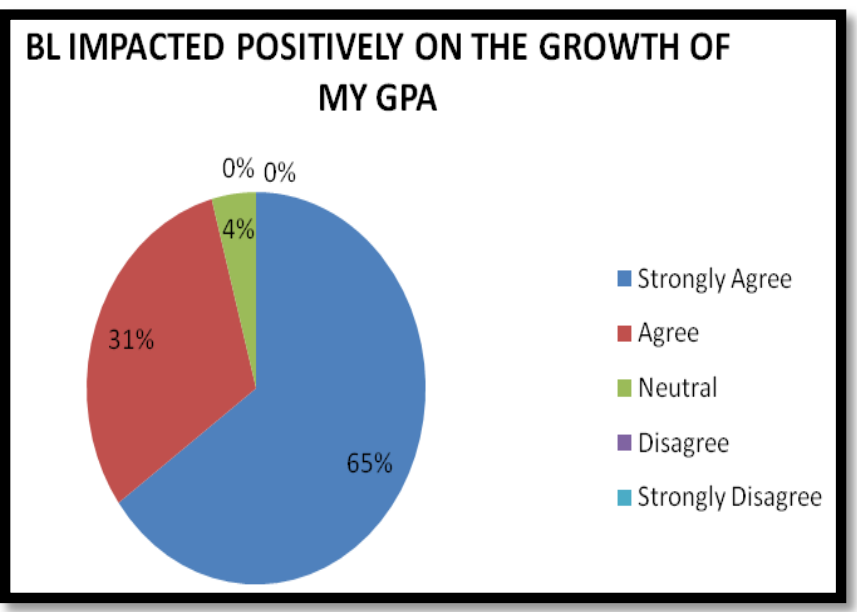

Fig. 16. Question 16 pie chart

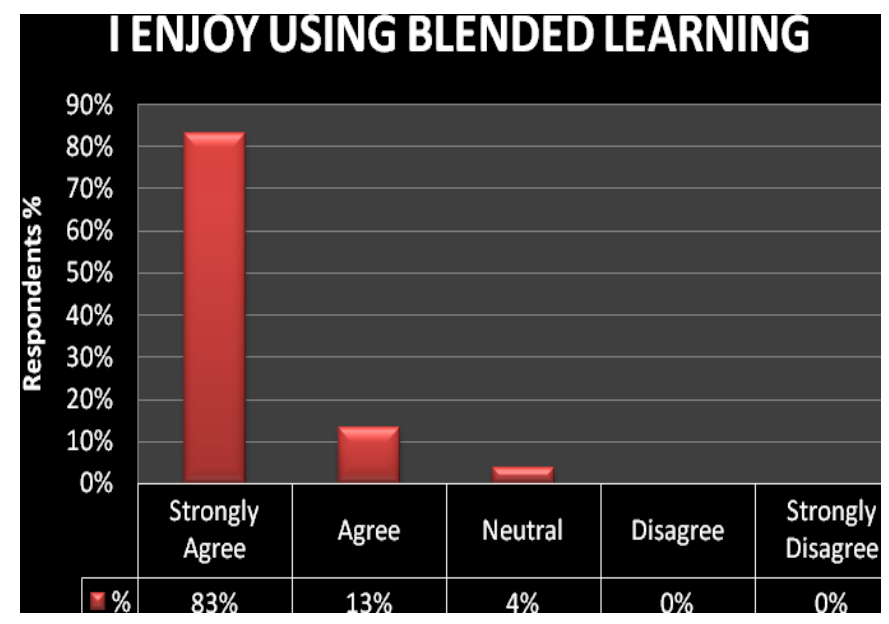

Fig. 17. Question 17 Column chart

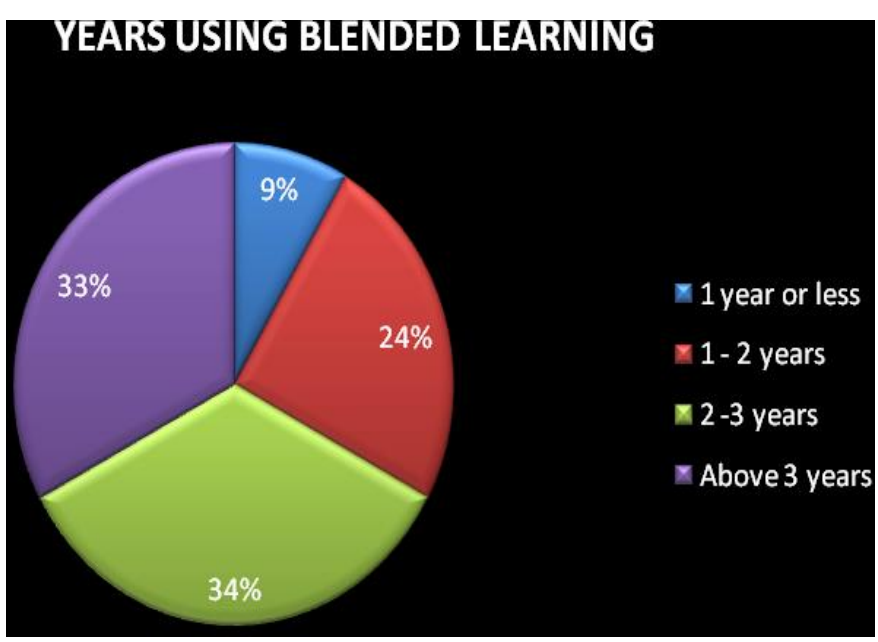

Fig. 18. Years using BL mode

X. PROPOSED FRAMEWORK

\section{A. Framework Introduction}

Upon completion of the presentation of results and analysis of the results, the researchers concluded by proposing a framework to monitor BL effects on students and students' perceptions on the same, as shown in Fig. 19. The framework takes note of the research questions and objectives of this study. Its input factors include the student factors, institution factors and the BL mode factors.

The authors combined the theoretical, logical and rational approaches to be able to develop the proposed framework [43] [44]. To establish the criteria and standards of the framework, the authors followed the literature review findings related to various $\mathrm{BL}$ frameworks, BL effects on students and perceptions with support from the participants of the questionnaire from Botho University.

The framework is modeled to indicate that the input factors which could affect the students' perceptions on the BL mode and the effects of the BL mode on students are the students, the institution and the BL mode. A triangulation of these factors is observed. The institutional factors, which include the institution characteristics, support and students' performance 
expectation plays an integral role in bridging the gap between the student and the BL mode to be used. The BL mode factors include among characteristics, internal and external factors, relevance, ease of use, quality output. These factors should constantly be monitored to ensure they complement the students' factors of student characteristics, students' perceptions and performance expectation together with the university factors. When all the factors are in mutual understanding of each other then they would foster an environment of acceptance and usage which would yield a positive effect on students and a positive perception.

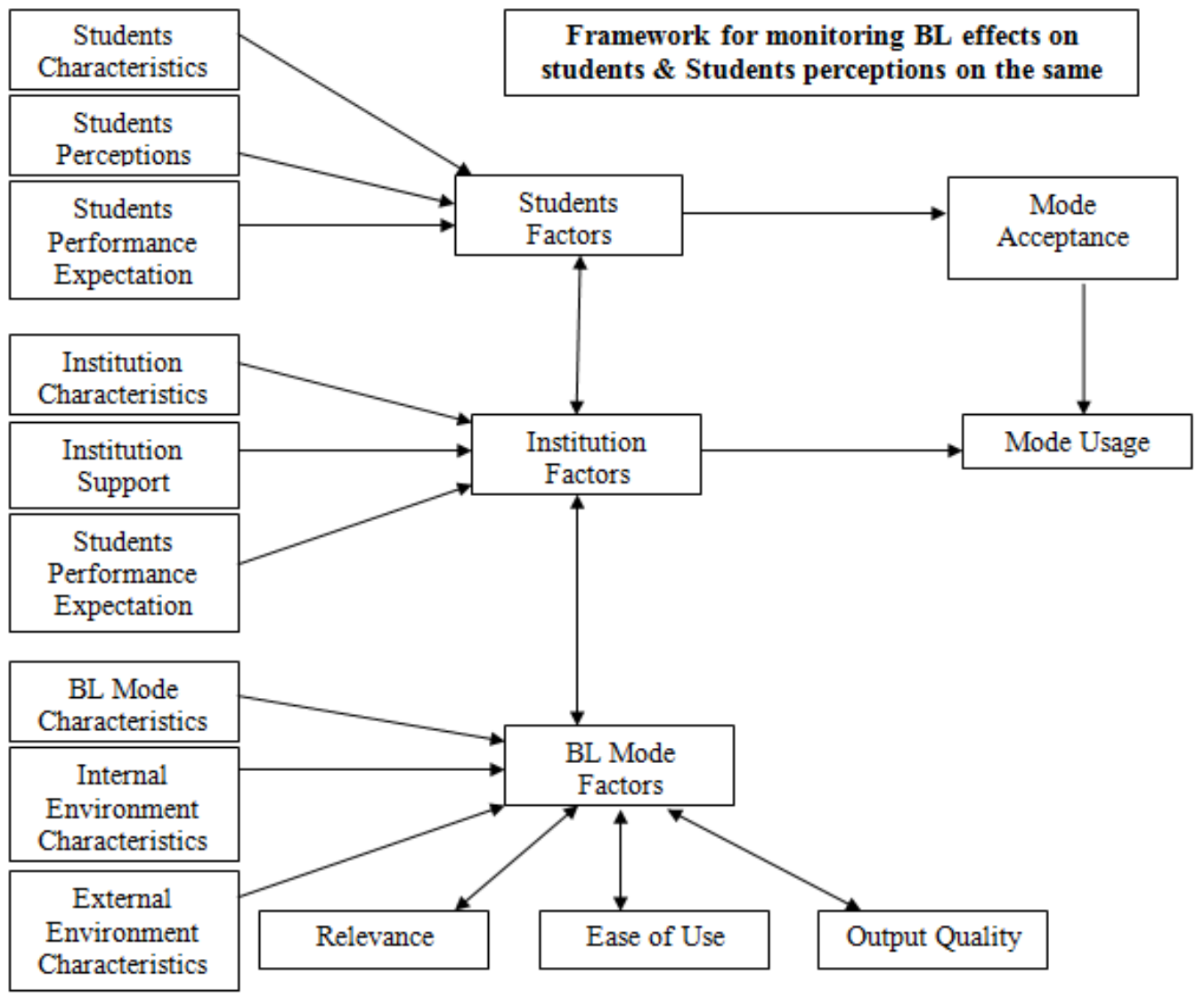

Fig. 19. Proposed framework

\section{B. Intended Use of the framework}

The framework would be used to BL mode effects on students and students' perceptions on the BL mode. The main purpose of the framework is to continual usage and appreciation of $\mathrm{BL}$ mode through a continuous process of referencing to the three inputs factors and their associated elements. It is essential for the Students, Institution and BL mode factors to be known and revised timely to ensure the integrity of the BL mode remains in place. The dynamism of today's education could impact individual entity factors, thus changing their known scope; hence an updating of them is important. Moreover, there should be a mutual balance between the Student, institution and BL mode factors hence, changes on the individual entities would necessitate a revision to ensure the framework still serves its purpose. When all the individual factors are in harmony, then acceptance of the mode by students and its usage is recognized.

\section{Implications of the proposed framework}

To realize the full potential of the framework in the academic setup, the following should be taken into consideration on its utilization.
1) The framework is meant to be an influential tool in the acceptance and (continual) usage of BL mode in institutions. It is imperative for all concerned stakeholders to engage with one another (students and institutions) to be able to identify and outline their factors and engage for constructive BL mode initiatives.

2) The framework act as a check tool. BL mode technologies keep on changing due to the nature of the technological setup of the modern-day society, hence it is important to continually check the relevance of the BL mode factors and elements and encourage the adoption of such technologies in line with relevance, ease of use and quality needed. Moreover, it would help institutions to re-align and determine areas of expertise and find ways of mutually assimilating BL mode in their areas and how they can be further developed for support of such in accordance with the various characteristics and or factors of the student cohort.

3) The framework is intended to act as a call up initiative in the Botswana educational set up for formation of research and discussion initiatives around the BL practice in tertiary institutions. This would ensure common understanding 
and expectation from all stakeholders at policy and system levels for finding ways to provide support mechanisms such as but not limited to resources, infrastructure and technologies for the growth of the BL mode in Botswana and its appreciation.

\section{RECOMMENDATION}

It is recommended that Institutions in Botswana review their curricula and find ways of adopting and assimilating the $\mathrm{BL}$ mode in their learning process.

With evidence that BL mode plays an important role in the student learning process, it is recommended that institutions, the private sector and the government of Botswana channel funds to the research of the utilization of BL mode.

\section{CONCLUSION}

It is concluded that the purpose of the study was achieved. The purpose was to investigate the effects of the BL mode on the students and the students' perceptions on the BL mode. This was achieved through meeting and addressing of the objectives and research questions outlined earlier. The study concludes that BL mode is important to students learning process. The evidence from the research carried shows that BL mode helps in knowledge gaining, and positively transforms learners' attitudes towards learning whilst also improve students' results. It also revolutionizes learners' critical thinking levels and dispositions. It is also concluded that there is acceptance of BL mode in a typical institution or university learning environment, as indicated by appreciation and satisfaction of respondents to the BL mode. Thus, it is highly appreciated. Therefore, in conclusion, BL mode has positive effects on tertiary students, and the students view it positively on their learning journey.

\section{FUTURE WORK}

More work need to be done on identifying why the institutions in Botswana are behind in the adoption of BL mode despite it having a favorable appeal to the students' community. Not only is it favorable, but studies as indicated in the literature review portion of this study it helps in attitudes molding and improvement of learners' results. In addition, studies should be carried out to identify the embracement of the BL mode in supporting the various learners (slow and quick learners). More work needs to be done on the proposed framework, as there are several positive implications this study and the proposed framework could have on the learning scope in Botswana.

As for the institutions not yet utilizing the BL mode, it is their opportunity to put in place the proposal of using such and follow the framework for identification and realization of $\mathrm{BL}$ mode. Those utilizing BL mode, could use the framework to re-evaluate their standing as per the current set up and find ways to moderate their findings. In addition, the researcher hopes to provide other researchers an opportunity to trial the framework. This framework is a proposed conceptual framework which relies heavily on the literature review and questionnaire findings, and as such a trial is needed with researchers own context to validate its standing and improvement.

The research was also constrained to the BL mode effects on students, and perceptions of students on the same, thus more need to be done to include all the relevant stakeholders. In this case, staff with focus on lecturers or academics, institutions management should be included. The views and perceptions of stakeholders lead to a more robust scope.

\section{ACKNOWLEDGMENT}

We would like to thank our sponsor Botho University for the continued support in upholding research. We also extend our appreciation to the Botho University community and the public for their input. Our greatest appreciation goes to the participants of this study, and finally our families.

\section{REFERENCES}

[1] Friedman, T. L. (2005). The world is flat: A brief history of the twentyfirst century. New York: Farrar, Straus, and Giroux.

[2] Nagel, D. (2009). Meta-analysis: Is blended learning most effective. The Journal Newman

[3] Wagner, T. (2008). The global achievement gap. New York: Basic Books.

[4] Garrison, D. R. and Kanuka, H. (2004). Blended learning: uncovering its transformational potential on higher education. Internet and Higher Education, 7, 95-105.

[5] Garrison, D. R., and Vaughan, N. D. (2008). Blended learning in higher education: Framework, principles, and guidelines. San Francisco: Jossey-Bass.

[6] Garrison, R., Anderson, T. and Archer, W. (2001). Critical thinking, cognitive presence, and computer conferencing in distance education. American Journal of Distance Education, 15(1), 7-23.

[7] Picciano, A. G., \& Dziuban, C. D. (Eds.). (2007). Blended learning research perspectives. Needham, MA: The Sloan Consortium.

[8] Laster, S., Otte, G., Picciano, A. G., and Sorg, S. (2005). Redefining blended learning. Paper presented at the Sloan-C workshop on blended learning, Chicago, IL.

[9] Mayadas, A., John, B., and Paul, B. (2009). Online education today. Science, 323(5910), 85-89.

[10] Dziuban, C., Hartman, J. and Moskal, P. (2004). Blended learning. Educause Review, 2004(7), 1-7.

[11] Graham, C. R. (2006). Blended learning systems. In C. Bonk (Ed.), The handbook of blended learning. Global perspectives and local designs (pp. 3-21). San Francisco: Pfeiffer.

[12] Shea, P. (2007). Towards a conceptual framework for learning in blended environments. In Blended Learning Research perspectives (pp. 19-36). Needham, MA: The Sloan Consortium.

[13] Republic of Botswana, (2012). Population of Towns, Villages and Associated Localities-Education. Gaborone: Government Printer.

[14] Wang T (2011),Developing Web-based assessment strategies for facilitating junior high school students to perform self-regulated learning in an e-Learning environment, Computers and Education,57, pp18011812.

[15] Rhema, A., and Miliszewska, I. (2014). Analysis of student attitudes towards e-learning: The case of engineering students in Libya. Issues in Informing Science and Information Technology, 11, 169-190.

[16] Kalantarrashidi, S.A., Mahammadpour, E. and Sahraei, F. Effect of Blended Learning Classroom Environment on Student's Satisfaction. Journal of Education and Training Studies.Vol. 3, No. 5; September 2015

[17] Kwak, D.W., Menezes, F.M. and Sherwood, C. (2013). Assessing the impact of blended learning on student performance.

[18] So, H.-J., \& Bonk, C. J. (2010). Examining the Roles of Blended Learning Approaches in Computer-Supported Collaborative Learning 
(CSCL) Environments: A Delphi Study. Educational Technology \& Society, 13 (3), 189-200.

[19] Mersal, F.A. and Mersal, N.A. Effect of Blended Learning on Newly Nursing Student's Outcomes Regarding New Trends in Nursing Subject at Ain Shams University. American Journal of Educational Research, 2014, Vol. 2, No. 11.

[20] Duhaney, D. C. (2004). Blended learning in education, training, and development. Performance Improvement, vol. 43, no. 8, pp. 35-38.

[21] Li Z., Tsai M., Tao J., Lorentz C. Switching to blended learning: The impact on students' academic performance. Journal of Nursing Education and Practice, 2014, Vol. 4, No. 3. 245-251.

[22] Melton, B., Graf, H., Chopak-Foss J. Achievement and Satisfaction in Blended Learning versus Traditional General Health Course Designs. International Journal for the Scholarship of Teaching and Learning, 2009; 3 (1), 1-13.

[23] Owston, R., York, D. and Murtha, S. Student perceptions and achievement in a university blended learning strategic initiative. Internet and Higher Education XXX (2013).

[24] Cohen, L., Manion, L. and Morrison, K. (2000). Research methods in education. 5th ed. London: RoutledgeFalmer.

[25] Saunders, M. et al. (2010). Organizational Trust: A Cultural Perspective. Cambridge: Cambridge University Press.

[26] Babbie, E.R. (2004). The practice of social research. Thomson/Wadsworth. Belmont, CA.

[27] Babbie, E.R., Halley, F. and Zaino, J. (2003). Adventures in social research: data analysis using SPSS 11.0/11.5 for Windows. 5th ed. California: Pinee Forge Press.

[28] Chilisa, B. and Preece, J. (2005). Research methods for adult educators in Africa: Pearson South Africa.

[29] Oates, B.J. (2006). Researching Information Systems and Computing. London: Sage.

[30] Bryman, A, Bell, E, 2007, Business Research Methods, 2nd edition. Oxford University Press.

[31] Creswell, J.W. (2003). Research design: a qualitative, quantitative and mixed method Approaches. 2nd ed. California: Sage Publications Inc.

[32] Creswell, J.W. (1994). Research design: qualitative and quantitative approaches. Thousand Oaks, CA: Sage Publications.

[33] Baker, T.L. (1994), Doing Social Research (2nd Edn.), New York: McGraw-Hill Inc.

[34] Patton and Cochran (2002). A Guide to Using Qualitative Research Methodology Available from http://fieldresearch.msf.org/msf/bitstream/10144/84230/1/Qualitative\%2 Oresearch\%20methodology.pdf (Accessed 13August 2016)

[35] Ackroyd, S. and J. A. Hughes, Data Collection in Context (1981) Longman

[36] Terre Blanche, M., Durrheim, K., and Painter, D. (Eds.) (2006). Research in practice: applied method for the social science. 2nd ed. Cape Town: University of Cape Town (Pty) Ltd.

[37] Kumar, R. (1996).Research Methodology: A Step-by Step Guide for Beginners. Longman, Australia

[38] Pérez-Marín, D. And Pascual-Nieto, I. (2012). A Case Study on the Use of Blended Learning to Encourage Computer Science Students to Study. Journal of Science Education and Technology, 21(1), 74-82.

[39] Delialioğlu, D. (2012). Student Engagement in Blended Learning Environments with Lecture-Based and Problem-Based Instructional Approaches. Journal of Educational Technology \& Society, 15(3), 310322.

[40] Lim, D.H. and Morris, M.L. (2009). Learner and Instructional Factors Influencing Learning Outcomes within a Blended Learning Environment. Journal of Educational Technology \& Society, 12(4), 282293.

[41] Hamilton, J. and Tee, S. Smart utilisation of tertiary instructional modes. Computers and Edcuation 54 (2010) Computers \& Education, 54, 4, pp. 1036-1053, Computers \& Applied Sciences Complete, EBSCOhost

[42] Bliuc, A., Ellis, R., Goodyear, P. And Hendres, D. (2011). Understanding student learning in context: Relationships between university students' social identity, approaches to learning, and academic performance. European Journal of Psychology of Education, 26(3), 417433.

[43] Brown, F. G. (1983) Principles of Educational Design and Psychological Testing, 3rd edn, Hoilt, Rinehart, and Winston, New York.

[44] Friedenberg, L. (1995) Psychological Testing: Design, Analysis and Use, Allyn and Bacon, Boston, MA. 